\title{
Predicting the Crimes Based on the Weather Using Pyspark
}

\author{
S. Selvakani, K.Vasumathi, M.Ajith
}

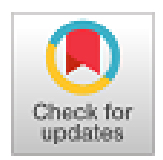

\begin{abstract}
Crime investigation is one in all the principal vital exercises of the greater part of the astute and authorization associations wherever the planet. Commonly they gather household partner degree remote crime associated data (insight) to stop future assaults and use a confined assortment of implementation assets in an ideal way. A genuine test Janus-looked by the greater part of the authorization and insight associations is with productivity and precisely investigating the developing volumes of crimes associated data. The Brobdingnagian geological decent variety and furthermore the nature of crime designs have made the breaking down and recording of crime data harder. Information preparing could be an incredible asset that might be utilized viably for examining gigantic databases and record vital expository outcomes. This paper presents partner degree astute wrong doing examination framework that is intended to beat the over referenced issues. The arranged framework is here is to propose area examination together with the crime occurred and that proposed Pyspark which is an open source clustering framework here to store incredible measure of information's for crime investigation. And the crime analysis is based on the arrest which is a classified graphically viewed using a chart based on yearly, monthly, weekly, daily crime to analyze the criminals data. The arranged framework comprises of an upscale and rearranged setting that might be utilized successfully for procedures of crime investigation.
\end{abstract}

Keywords: crimes, attacks, pyspark, analyzing.

\section{INTRODUCTION}

Crime investigation has turned out to be one in all the chief imperative exercises of the in vogue world on account of the high size of violations that might be consequences of innovative headway and furthermore the development. Requirement associations and furthermore the knowledge gathering associations all round the world ordinarily gather mammoth measures of local and outside crime data (insight) to stop future assaults [1]. As this includes a larger than usual amount of learning, manual systems of dissecting such data with a boundless variety have brought about lower efficiency and inadequate use of work drive. This is frequently one in all

Revised Manuscript Received on October 30, 2019.

* Correspondence Author

Dr. S. Selvakani*, Assistant Professor and Head, Department of Computer Science, Thiruvalluvar University College of Arts and Science, Arakkonam.

K.Vasumathi, Assistant Professor, Department of Computer Science, Thiruvalluvar University College of Arts and Science, Arakkonam

M.Ajith, Research Scholar, Department of Computer Science, Thiruvalluvar University College of Arts and Science, Arakkonam

(C) The Authors. Published by Blue Eyes Intelligence Engineering and Sciences Publication (BEIESP). This is an open access article under the CC BY-NC-ND license (http://creativecommons.org/licenses/by-nc-nd/4.0/) the first prevailing issues in a few requirement and knowledge associations. There are numerous crucial purposes behind crime investigation like to spot general and explicit wrongdoing patterns, designs, related arrangement in a current, opportune way, to amplify the use of limited implementation assets, to get to crime issues territoriality, locally, the nation over at interim and between authorization organizations, to be proactive in criminologist work and avoiding violations and to satisfy the requirement wants of the regularly evolving society. There are various wrongdoing information preparing procedures available like bunch systems, affiliation rule mining, continuous example mining, and order and string examination. A few web basically put together wrongdoing mapping frameworks are with respect to the market on the net like opiates arrange in urban focus nearby office, anyway larger part of them are uniquely made for administrative experts in various nations and individuals frameworks don't appear to be open to parties outside that particular implementation or authoritative specialists.

\section{SURVEY OF TECHNOLOGY}

In numerous nations the measure of crime episodes that is agreeing every day is expanding significantly. Concerning Ceylon, The division of Police is that the most imperative association of averting wrongdoings. Also, a critical test confronting all law-implementation and insight gathering associations is precisely and with productivity examining the developing volumes of crime learning. Police examination crime can in like manner be incredible as after effects of occupied system traffic and incessant on-line exchanges create enormous measures of information, only tiny low bit of that identifies with illicit exercises. Preparing might be a strong apparatus that empowers criminal agents World Health Organization would conceivably need escalated function as information investigators to investigate enormous databases rapidly and quickly. Furthermore, as of late the mining is data breaking down strategies that acclimated investigate wrongdoing information beforehand hang on from shifted sources to chase out examples and patterns in violations [2]. In further, it'll be connected to expand effectiveness in assurance the wrongdoings quicker and may even be connected to consequently illuminate the violations. It examinations a couple of all totally unique true violations data sets for urban focus, $\mathrm{CO}$ and la, CA and gives a correlation between the two data sets through a connected science examination upheld by a few charts. Related all through this paper we tend to will in general propose Associate in Nursing approach for wrongdoing expectation and grouping exploitation handling for port of passage.

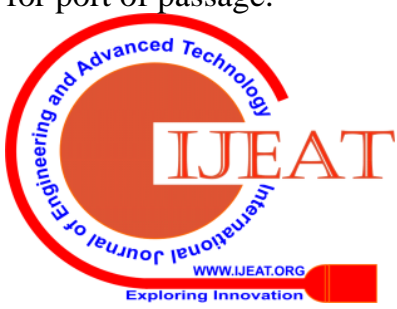




\section{Predicting the Crimes Based On the Weather Using Pyspark}

The methodology is examination a couple of kinds of groupings: the K-NN classifier and conjointly the Naïve researcher classifier.

At interim the K-NN classifier, a couple of all totally extraordinary procedures were performed uniform and reverse. Though at interim the Naïve researcher, Gaussian, Bernoulli, and Multinational methods were tried. Approval and cross approval were acclimated check the aftereffects of every method. The exploratory outcomes demonstrate that we tend to zone unit prepared to gain resulting order exactness by exploitation multinational Naïve researcher exploitation crosses approval. Also, and so on.,

\section{METHODOLOGY}

\section{A. Existing System}

The framework might be an electronic framework that incorporates of wrongdoing investigation strategies like hot spot recognition, crime correlation and crime design perception.

Framework can't be legitimately substantial abuse records of the bureau of nearby government because of police records grasp each major and minor crime occurrences. The framework depends on paper articles subsequently it incorporates exclusively a lot of complete crime occurrences [3]. Along these lines singular pieces of the framework region unit assessed and aftereffects of that examination are wont to quantify the adequacy.

Crime information handling is that the use of data digging strategies for wrongdoing examination. Shifted looks into are distributed amid this space. Violations might be isolated into subcategories upheld very surprising criteria. In eight wrongdoing classes are given [4]. They are criminal traffic offenses, sex wrongdoings, burglary, misrepresentation, and fire related crime, medicate offenses, cyber-crimes and brutal violations.

There were a few endeavors to explore types varying sorts of violations abuse machine-controlled systems anyway there's no bound together structure depicting an approach to apply those methods to entirely unexpected crime types. In, they need utilized a structure which fuses a connection between the crime information handling system and crime kind qualities [5], [11], [12]. There are many existing frameworks that utilization crime information preparing procedures for crime examination like, local crime investigation program, information handling structure for crime pattern identification and narcotics network in city department of local government.

An intelligent crime identification system is delineated within which may be wont to predict doable suspects for given crime [9]. They need used 5 kinds of agents specifically, message area agent, entry agent, unfortunate person agent, criminal agent and proof agent.

\section{B. Proposed System}

The planned system consists of a fashionable and simplified setting that may be used effectively for processes of crime analysis. We have a tendency to planned pyspark for classification and datasets area unit hold on into sparksql storing and retrieval of data are going to be quicker
1. Arranged data examination along the edge of crime data to investigation and anticipate that area makes a ton of crime move and portrayed wrongdoing examination with graphical delineation

2. Predicted the capture upheld year, month, week and day and high five crime in 2012, 2013, 2014, 2015, 2016, 2017 in month, week and day astute and that anticipated area examination that area had a great deal of assortment of violations with network space and Arrest has been dissected with crime and arranged with chart for a ton of precision figuring.

\section{SYSTEM DESIGN AND IMPLEMENTATION}

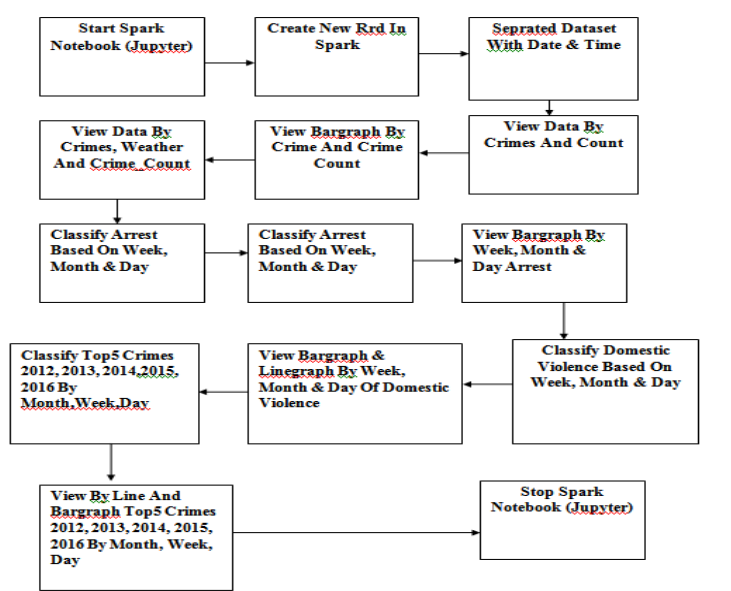

Fig 1 System Architecture

\section{A. Basic Modules}

1. Svm Pre-Processing

2. obtaining Column Temperature, Crime partitions and Events

3. supply Regression Accuracy Calculation

4. Finding high five Crimes With Year, Month, Week \& Day Analysis On 2012, 2013, 2014, 2015 \& 2016, 2017

5. K-Nearest Neighbour (KNN)

\section{Svm Pre-Processing}

A Support Vector Machine (SVM) is AI algorithmic program that breaks down information for characterization and multivariate examination. SVM might be a regulated learning technique that shows up at information and sorts it into one in each of the 2 classes. Partner in Nursing SVM yields a guide of the arranged learning with the edges between the 2 as such a great amount of separated as potential. SVMs are utilized in content order, picture arrangement, and penmanship acknowledgment and inside the sciences. A help vector machine is moreover called a help vector organize Import perform for pandas has been wont to spare knowledge set and read_csv has been made as factors Printing the sort violations to bring up information outline together with import capacities read Uploaded data set by evacuating introductory 3 segments by misuse capacities

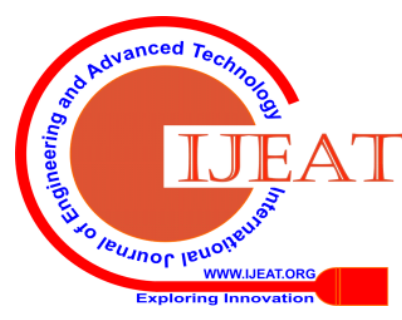


and heading the rest of the sections with date as principle header.

\section{Obtaining Column Temperature, Crime Sorts And Events}

Groupby Columns with Count Getting column temperature (Fahrenheit, Event and crime kind (Primary type) and count by exploitation groupby perform we tend to take away duplicate columns and consider high fifteen info from the cri_count type.

Choosing Event from DatasetShape Cri_Count shows the rows and column from retrieved kind. Obtaining Event from dataset and head chosen column from dataset.

Graph Creating the event count kind get Event together with count by exploitation cluster by we tend to scale back duplicate values plotting graph using by crime count with weather type

\section{Supply Regression Accuracy Calculation}

Logistic regression is conceptually like regression toward the mean, wherever regression toward the mean estimates the target variable. Rather than predicting values, as within the regression toward the mean, supply regression would estimate the chances of a particular event occurring.

Logistic regression Gets yearly arrest worth, Monthly arrest, weekly arrest values and daily arrest values to provide line map and predict the event of arrest

Plotting a graph with yearly, week and day Resample predefined perform wont to classify year, week and day arrest A is employed for year and $\mathrm{W}$ is used for Week and $\mathrm{M}$ is used for Month and D is used for day. Line is employed to plot graph.

\section{Finding high five Crimes With Year, Month, Week \& Day Analysis On 2012, 2013, 2014, 2015} \& 2016, 2017

Creating kind from to 2012 to 2017 with Crime type [primary types] column and heading the column and plotting with year, Month, Week, Day with high five crimes.

\section{K-Nearest Neighbour (KNN)}

K-Nearest Neighbour (KNN) classification is employed for crime prediction. The projected system can predict regions that have high chance for rate and might forecast crime prone areas, rather than that specialize in causes of crime incidence like criminal background of bad person, political enmity etc it'll focus chiefly on crime factors of every day.

- obtaining location description and first sorts with count

- Location description with arrest analysis together with latitude

- exploitation location specifically community space

- Total rate.

\section{B. Implementation}

1. Tools used here is pyspark, jupyter console ,anaconda \&amp; SparkSql

2. Spark and jupyter ought to be connected with bashrc path for notebook to begin

3. Command to begin notebook is pyspark --driver-memory $8 \mathrm{~g}$--executor-memory $4 \mathrm{~g}$--master local[4]

4. Dataset can load with some spark import. Loaded dataset are going to be retrieved by omitting initial three column

5. Retrieve primary_type column and used groupby and count to retrieve key and values as output.

6. Retrieved output are going to be generated with bar chart that is crime activity and counts

7. currently we are going to classify Yearly arrest ,Monthly arrest and daily arrest by obtaining year column

8. The output of yearly arrest , Monthly arrest and daily arrest are going to be viewed in line graph

9. Currently we are going to classify high five crimes happened in month ,year \&amp; day with bar chart in month and different are going to be line graph

10. Currently we are going to analysis weather knowledge by plotting in bar chart.

\section{RESULT AND DISCUSSION}

\section{A. Testing Report}

\section{Import Function}

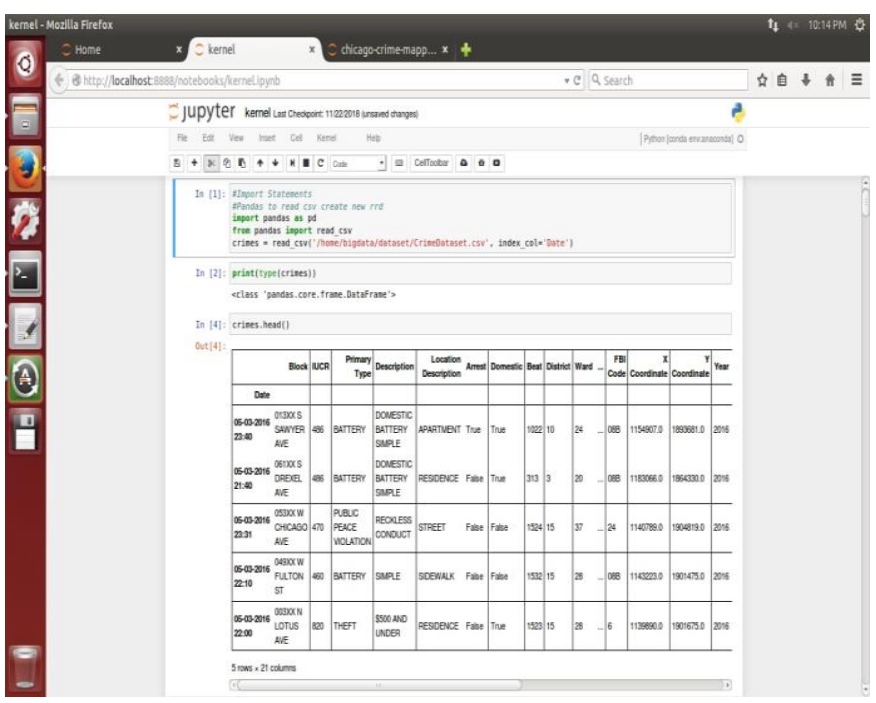

Fig 2 import function

Import Function for pandas has been used to save dataset and read csv has been created as variables and printing the type crimes to show data frame along with import functions.

\section{View Report}

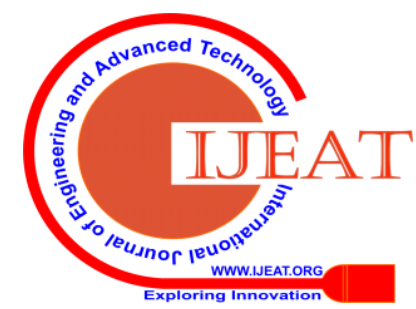




\section{Predicting the Crimes Based On the Weather Using Pyspark}

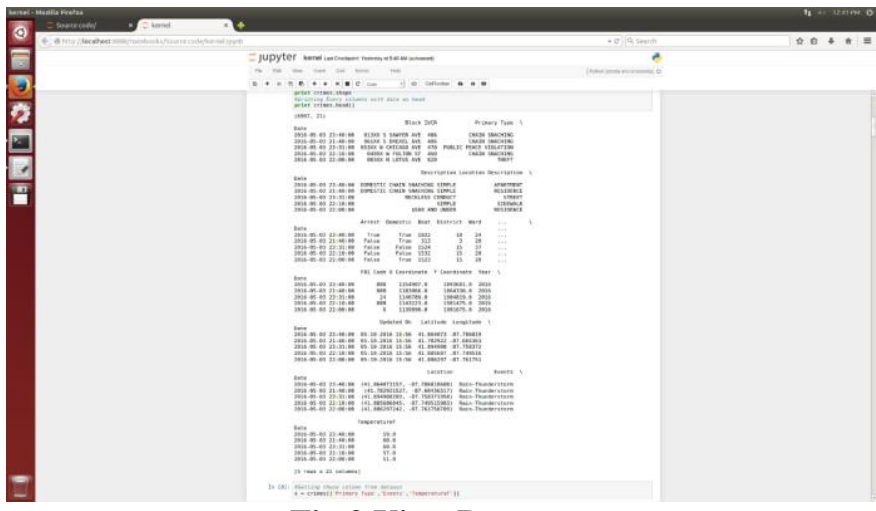

Fig 3 View Dataset

In fig 3 View module is used to upload the dataset by removing first three columns by using iloc functions and heading the remaining columns with date as main header.

\section{Getting Column Temprature, Crime Types And Events Groupby Columns With Count}

\begin{tabular}{|c|c|c|c|}
\hline & Primary Type & Events & Temperaturef \\
\hline $\begin{array}{ll}\text { Date } \\
05-03-2016 \quad 23.40\end{array}$ & & & \\
\hline $05-03-2016 \quad 23: 40$ & BATTERY & Rain-Thunderstorm & 59.0 \\
\hline $05-03-2016 \quad 21: 40$ & BATTERY & Rain-Thunderstorm & 60.0 \\
\hline $05-03-2016 \quad 23: 31$ & PUBLIC PEACE VIOLATION & Rain-Thunderstorm & 60.0 \\
\hline 05-03-2016 22:10 & BATTERY & Rain-Thunderstorm & 57.0 \\
\hline $05-03-2016 \quad 22: 00$ & THEFT & Rain-Thunderstorm & 51.0 \\
\hline
\end{tabular}

Fig 4 Getting column temp, crime types and events

In fig 4 the crime types, events and temperature is grouped using the groupby columns using count to group the crime details for further classification.

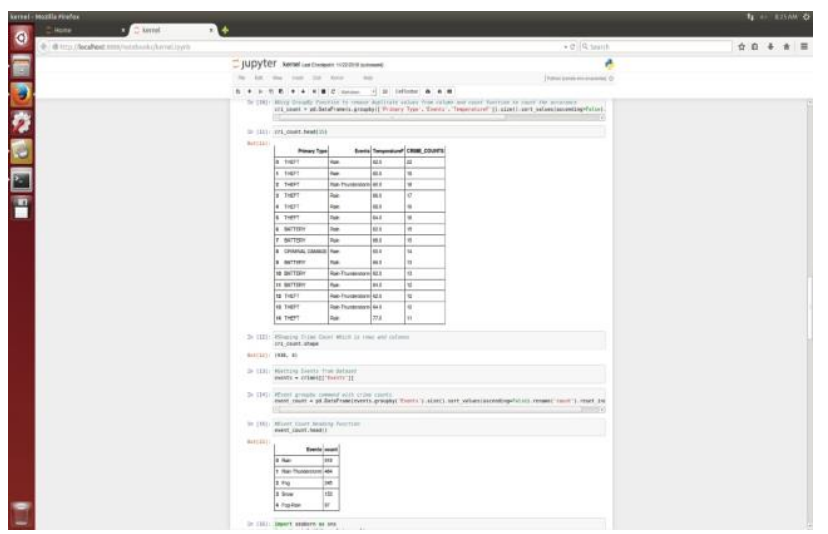

Fig 5 Groupby column with count

In fig 5 we Get column temperature (Fahrenheit, Event and crime type (Primary type) and count by using groupby function we remove duplicate columns and view top 15 information from the cri_count type.

\section{Crime Count With Weather Data}

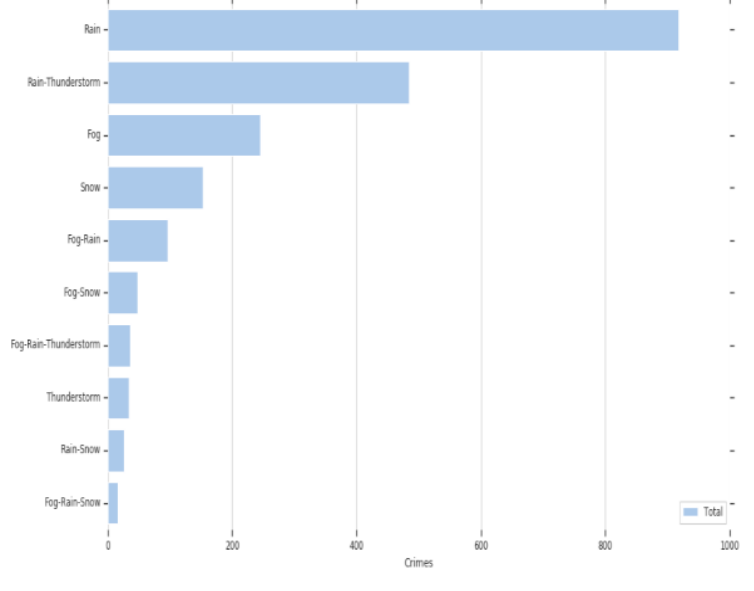

Fig 6 Crime count with weather data

In fig 6 we Creating the event_count type get Event along with count by using groupby and counting crimes we reduce duplicate values plotting graph with weather type.

\section{Crime Count With Crime Types}

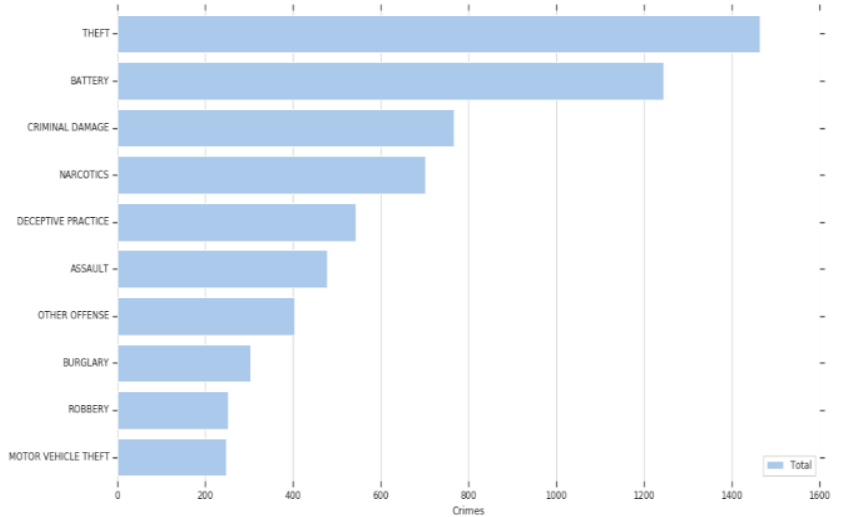

Fig 8 Graphical view of Crime type and crime count

In fig 8 we Create Crime count to get Primary types (crime types), and by using groupby function we reduce duplicate values from data plotting graph with Crime types and Crime Count.

\section{Arrest Based on Yearly, Month, Week, Daily \&Amp; Date}

\section{Algorithm: Logistics Regression}

Logistic regression is employed to predict outcomes or responses.

Logistic regression is conceptually just like simple regression, wherever simple regression estimates the target variable, rather than predicting values, as within the simple regression, logistical regression would estimate the percentages of a specific event occurring.

Logistic regression Gets yearly arrest worth, Monthly arrest, weekly arrest values and daily arrest values to supply line map and predict the event of arrest.

Different visual images of crime areas and domestic violance are shown in Y,M,W,D formats in fig 8, 9 and 10.

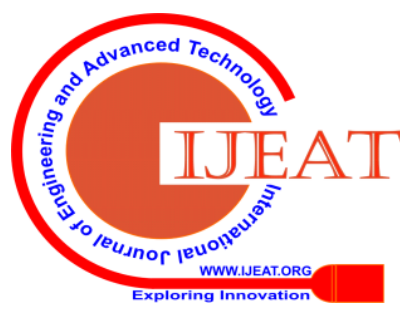




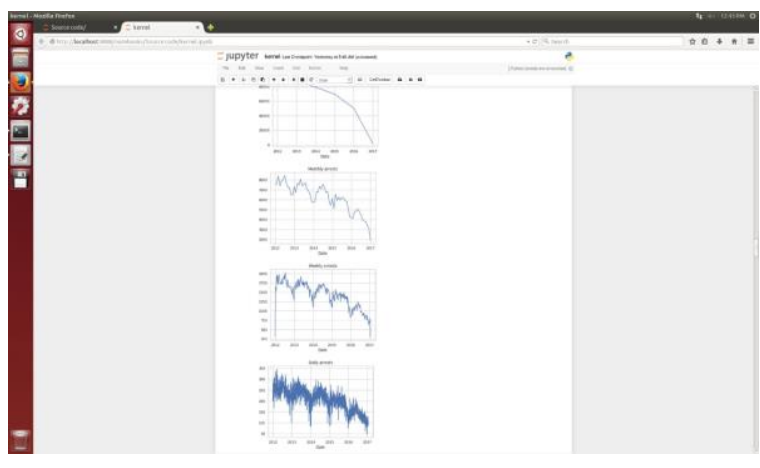

Fig 8 Y, M, W, D arrest Graph

Creating type from to 2012 to 2017 with arrest column and heading the column and plotting with yearly arrest.

Plotting a graph with yearly, week and day Resample predefined function used to classify year, week and day arrest $\mathrm{A}$ is used for year and $\mathrm{W}$ is used for Week and $\mathrm{M}$ is used for Month and D is used for day. Line is used to plot graph.

\section{Domestic Violence}

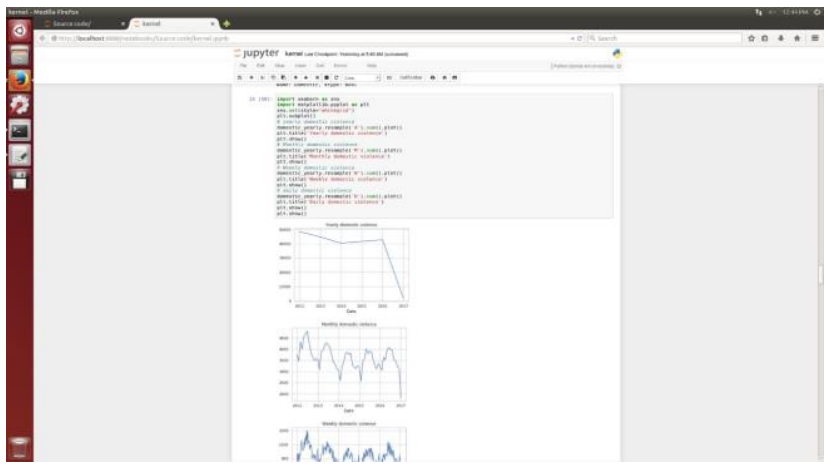

FIG 9 Y, M, W, D Domestic Violence Graph In

8. Finding Top 5 Crimes With Year, Month, Week \& Day Analysis On 2012, 2013, 2014, 2015 \& 2016,2017

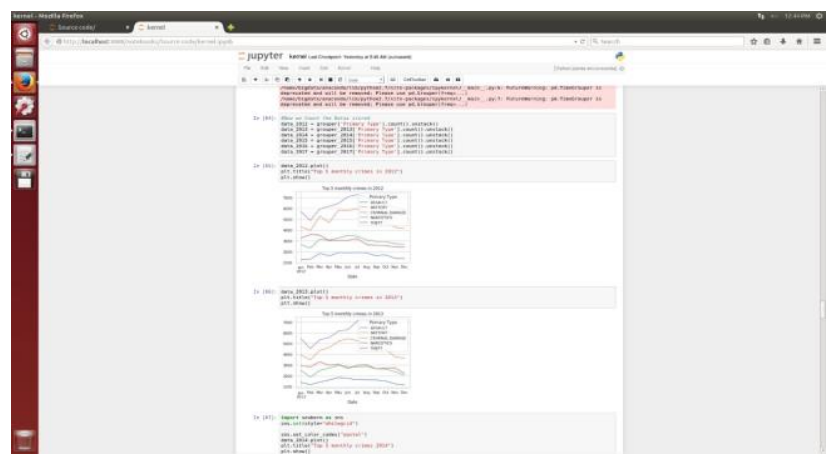

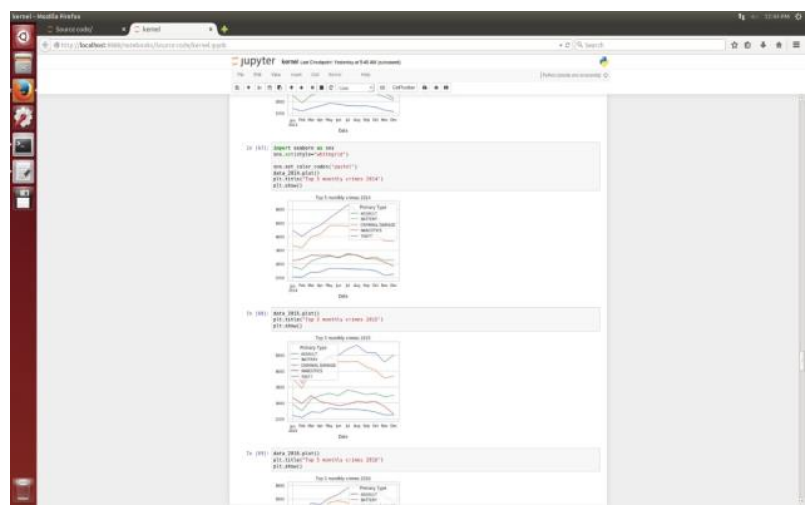

Fig 10 Top 5 Y,M,W,D crimes in 2012 to 2017 Graph

\section{CONCLUSION}

The project's objective is to investigate using the crime knowledge and supply fruitful suggestions to the department of security, to safeguard the precincts and beats wherever the crime rates are high. Here, we have a tendency to use the various regression, clustering, classification and frequent growth patterns so as to prepare and arrange the information in an exceedingly ordered fashion. The yearly, monthly, weekly, daily arrest classification for the crime analysis and easy to retrieving dataset. Therefore I may ascertain that the analysis if applied on the acceptable knowledge would lead to generating patterns that might facilitate to spot the crime rate early, and the feature work start for current crime data analysis in yearly, monthly, weekly, daily arrest based on the types of crimes.

\section{Future Scope of the Project}

Features provided by the platform

1. Redraw economical police jurisdiction boundaries.

2. Question knowledge within the crime dataset.

3. Draw economical police patrol beats supported the crime distribution.

4. Predict crime classes for a given crime situation.

5. transfer against the law dataset and population dataset.

6. Preprocess the uploaded crime dataset.

7. Discover special and temporal patterns of crime knowledge victimization mental image options.

\section{REFERENCES}

1. BURSIK, R., AND GRASMICK, H. Neighborhoods and Crime: The Dimensions of Effective Community Control. Lexington Books, Richard Rosenfeld University of Missouri-St. Louis, 1993.

2. BRAITHWAITE, J. Crime, shame and reintegration. Cambridge University Press, 1989.

3. ANSELIN, L. Under the hood: issues in the specification and interpretation of spatial regression models. Agricultural economics 27, 3 (2002), 247-267.

4. ANSELIN, L., COHEN, J., COOK, D., GORR, W., AND TITA, G. Spatial analyses of crime. Criminal justice 4, 2 (2000), 213-262.

5. Crime mapping report mobile application using GIS [Online]. Available:

6. https://www.crimereports.com/A Fuzzy Grey Cognitive Maps-based intelligent security system [Online]. Available: http://maps.met.police.uk

7. BJS. "rates of violent victimizations, 1993-2015" and "rates of property victimizations, 1993-2015". Generated using the NCVS Victimization Analysis Tool at http://www.bjs.gov, 2016. Bureau of Justice Statistics, 17-Nov-2016.

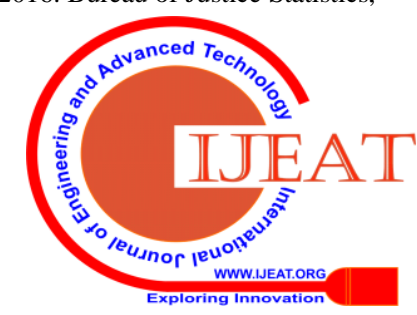




\section{Predicting the Crimes Based On the Weather Using Pyspark}

8. https://www.datacamp.com/community/tutorials/tutorial-jupyter-noteb ook

9. P. Chamikara, D. Yapa, R. Kodituwakku and J. Gunathilake, "Intelligent criminal identification system," International Journal of Soft Computing and Engineering, vol. 2, no. 1, pp. 175-180, 2012.

10. H. Chen, W. Chung, J. Xu, G. Wang, Y. Qin and M. Chua, "Crime data

11. Mining: a general framework and some examples," IEEE Explore-Computer, vol. 37, no. 4, pp. 50-56, 2004.

12. R. Krishnamurthy and S. Kumar, "A survey of data mining techniques for analyzing crime patterns," International Journal of Data Mining Techniques and Applications, vol. 1, no. 2, pp. 117-120, December 2012.

13. WANG, H., KIFER, D., GRAIF, C., AND LI, Z. Crime rate inference with big data. In Proceedings of the 22nd ACM SIGKDD International Conference on Knowledge Discovery and Data Mining (2016), ACM, pp. 635-644.

14. WANG, H., KUO, Y.-H., KIFER, D., AND LI, Z. A simple baseline for travel time estimation using large-scale trip data. In Proceedings of the 24th ACM SIGSPATIAL International Conference on Advances in Geographic Information Systems (2016), ACM, p. 61.

15. GERBER, M. S. Predicting crime using twitter and kernel density estimation. Decision Support Systems 61 (2014).

16. GORMAN, D. M., SPEER, P. W., GRUENEWALD, P. J., AND LABOUVIE, E. W. Spatial dynamics of alcohol availability, neighborhood structure and violent crime. Journal of studies on alcohol 62, 5 (2001), 628-636.

17. GRAIF, C. Toward a geographically extended perspective of neighborhood effects on children's victimization. American Society of Criminology Annual Meeting (2015).

18. BRANTINGHAM, P., AND BRANTINGHAM, P. Criminality of place. European journal on criminal policy and research 3, 3 (1995), 5-26.

\section{AUTHORS PROFILE}

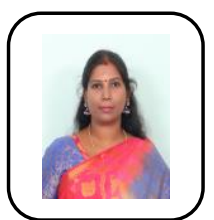

Dr. S. Selvakani is currently working as the Head of the Department of Computer Science and Applications, Thiruvalluvar University College of Arts and Science. She completed her Ph.D in Computer Science in the year 2009 in Mother Teresa University. A holder of M.Tech and MCA, M.Phil gives her the acumen to engage in research in mobile computing. As a proficient student, she has graduated her MCA with University Rank 3 from Manonmanian Sundaranar University and MPhil with Distinction from Madurai Kamarajar University. She began her career as lecturer in Bharathiyar University in 2002 and since then has worked in colleges in Chennai and Tirunelveli. Her single longest work experience is with Francis Xavier Engineering College, Tirunelveli as the Head of the Department for over 7 years.

Dr. S. Selvakani has been an active researcher throughout her career. She has published 70 papers in international journals / Conferences including Elseiver, Inder Science etc. Her research experience has earned her accolades as reviewer for International Journals like SPRINGER - WINE. As a well-known academic, she has chaired many sessions and has been the guest speaker in both National and International conferences. She is a member of Board of Studies for various reputed Autonomous Colleges and a Question paper setter for Bharathiar University, Madras University and various Deemed Universities.

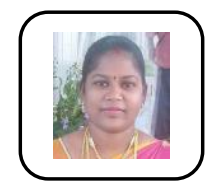

K.Vasumathi , Serving as an Assistant Professor in the department of computer science, Completed BSC MSC(IT), MPhil and SET in the Field of Computer Science. She is an eminent Scholar. A Strong hard worker with 9 Years of Teaching Experience

M.Ajith doing his MSC Computer Science at Thiruvalluvar University College of Arts and Science 